\title{
The quality of life in Crohn's disease
}

It is a truism that the 'quality of life' should be the most important consideration in the management of patients with any disease. This is particularly so for life long diseases like Crohn's disease, which are not curable, subject to remissions and relapses, and probably lead to an excess mortality throughout life. ${ }^{1}$ The quality of life of an individual patient obviously depends on many pre-existing and unalterable factors such as socioeconomic status, intelligence, age and premorbid personality. A patient's life prospects will also, however, be affected by the knowledge the patient has about his disease, his perceived future prospects as indicated by professional attendants, and perhaps most importantly by the treatment. Despite its importance the assessment of the quality of life has received relatively little attention in the literature; indeed, before 1976 this was not a subject heading in the Cumulated Index Medicus. There are some exceptions to this lack of data which include detailed studies of the quality of life in patients on dialysis, ${ }^{2}$ patients with arthritis, ${ }^{3}$ and with chronic obstructive pulmonary disease. ${ }^{4}$ The curtailment of independence by arthritis and life long dialysis and the mental impairment associated with hypoxia make these papers of limited value in assessing the likely impact of Crohn's disease on life style.

There are a number of difficulties in assessing the quality of life in Crohn's disease which has led to the scant attention it has received in the literature. First, most Crohn's sufferers have periods of health punctuated by illness. The judgment of the quality of life will therefore vary markedly depending on the time of the survey. Second, an analysis is of limited value unless it contains a full cross section of patients with the disease. This is particularly difficult to obtain in Crohn's disease where ill patients tend to collect in referral centres and other patients default because they are doing well. Indeed, it was suggested in one study that the predominance of men attending the outpatient clinic with high scores for neuroticism on the Eysenck personality questionnaire was because they were more willing to miss time off work than those with a 'normal' personality profile. ${ }^{5}$ The third difficulty with research into the quality of life in Crohn's is the perception that no scientific method exists for its measurement and it remains a complex and elusive concept. This attitude can be summarised by Dubois ${ }^{6}$ who defined quality of life as attaining 'profound satisfaction from the activities of daily life' and added that such value judgments are 'highly subjective'. Indeed all the surveys of quality of life in Crohn's disease only attempt a subjective assessment by the patients of their own perceptions of life style. Recent research, however, has shown that random samples of well Americans, and of those with chronic disease are able to categorise very similar areas of their life which make up an overall quality of life index. 
Perhaps not surprisingly, these include physical and material well being, relationships with other people, social and community activities, personal fulfilment and development and recreation. ${ }^{7}$ Attempts have been made to produce standardised questionnaires and scoring systems which incorporate some or all of these areas. The Stamford Health Assessment questionnaire concentrates on pain and disability, ${ }^{8}$ while the McMaster Health Index questionnaire covers physical disability, social role performance, emotional function, including feelings towards personal relationships and self esteem. ${ }^{3}$ This latter health questionnaire can be transformed into a mathematical score, is applicable to a range of diseases and has been validated against other similar questionnaires, such as the Spitzer Quality of Life Index." Other scales include the sickness impact profile and the quality of well being scale. ${ }^{4}$ This latter is particularly interesting in Crohn's disease because it includes a measure of the excess mortality by assessing the 'well life expectancy', which is the calculated survival in years reduced by a formula which takes account of the degree of disability which is likely to be encountered.

The plethora of questionnaires available strongly suggest that none is entirely satisfactory, but this is not surprising in trying to assess something as subtle and complex as the quality of life. As no universally acceptable criteria of quality of life is available all these questionnaires have been assessed by obtaining empirical evidence supporting their usefulness; the so called 'construct validation'. Useful correlations in Crohn's disease might include a Crohn's disease activity index, subjective assessments by patients and relatives, and personality and psychological ratings. As the indices of quality of life have been developed in the United States, they need reassessing in the different cultural environment of Britain to see if they provide a helpful measure in the context of Crohn's disease.

There are five studies which attempt to assess the quality of life in patients with Crohn's disease, one of which is published in the current issue of Gut. Three of these primarily assess surgical patients. The study of de Dombal et $a l^{10}$ reviews the long term prognosis of surgery for Crohn's disease, but mentions that $20 \%$ of medically treated patients compared with $70 \%$ of surgically treated patients were free of all symptoms at the time of interview. Steinberg et $a l^{11}$ reviewed the effects of an ileostomy on patients with ulcerative colitis or Crohn's disease using a modified type of Visick grading. Ninety five per cent had good or excellent results in ulcerative colitis compared with only $70 \%$ in Crohn's disease because of local stoma problems and recurrence. In the other study of surgery in Crohn's disease, Myers and his colleagues ${ }^{12}$ interviewed 51 patients and asked a series of specific questions about personal relationships, job performance, body image and sexuality, although insufficient detail is given in the text to obtain meaningful degrees of dysfunction in these areas. The prime conclusion is, perhaps not surprising, that before surgery there was a considerable overall patient dissatisfaction affecting most aspects of their life, which improved postoperatively. Ileostomy patients were less satisfied, particularly with regard to body image and patients with recurrent disease also fared less well except with regard to sexuality. The degree of overall satisfaction with the results of surgery was high and increased with time. Only $8 \%$ of those studied would in retrospect have refused an operation. The most serious criticism of this retrospective review is that the perception by most patients of events before 
surgery is likely to be distorted by the psychological impact of a major operation and the desire to feel better as a result.

The quality of life assessed in an ill group of 88 surgically and medically treated patients is likely to be unnecessarily pessimistic, as a quarter of the patients were receiving treatment with antidepressants, and three-quarters with immunosuppressive drugs or steroids. ${ }^{5}$ This study showed that the personality profile of the patients were similar to a control population and that the degree of neuroticism, or extroversion, as assessed by the Eysenck personality questionnaire and morbid anxiety index were a more important determinant of quality of life than the objective severity of disease measured by the Crohn's disease activity index. This finding is predictable and has been confirmed by studies in other chronic diseases. ${ }^{13}$ Although many patients had major health worries and marital problems, only five were made redundant as a result of their health and many were able to insure their lives at normal premiums. Some patients felt that their interpersonal relationships had in fact improved as a result of their disease which had 'brought them closer together', although sexual activity was diminished in all but 12 patients.

One of the strengths of the study of quality of life in Crohn's disease reported in this issue of Gut (Sørenson, Olsen and Binder, p. 382) is that a representative cross section of patients with Crohn's disease in Copenhagen were studied, only a minority of whom were receiving antidepressants or steroids. Another advantage is that a similar questionnaire was administered to a control group of patients with an acute short term illness. The most striking finding is that the marital relationships, recreational, social, and employment activities are not different between Crohn's disease patients and the 'controls'. Most patients, however, felt that the quality of life was diminished by the disease, particularly during exacerbations. The differences in the severity of the disease studied may account for the normal sexual function of the patients from Copenhagen compared with those in London, but it is more difficult to explain the prediction that up to $20 \%$ of the Danish patients with Crohn's will retire for health reasons during the next 10 years.

It is in my view very important that further information is obtained about quality of life in Crohn's disease. Many patients ask for further facts about their disease. Indeed in the study from London over a third of patients had consulted medical and nursing text books about their condition, but had found this information unhelpful. This desire for more information reemphasises the importance of extensive counselling during the initial phase of the diagnosis, and stresses the need to consider including other members of the health care team, such as social workers, at this stage. Increasing technological advances in medicine have been associated with a growing volume of complaints about the dehumanising aspects of medical care. ${ }^{14}$ Social workers are specifically trained in the analysis of coping mechanisms and adaptive responses in patients to life threatening illnesses and have much to offer in assessing the likely outcome in individual patients. ${ }^{15}$ It seems likely that the ability to cope is markedly influenced by access to information about the likely physical and psychological consequences of disease, and where possible participation in decision making with regard to different forms of treatment.

Further information is also urgently required on the comparative quality 
of life in patients treated medically and surgically. There are suggestions in the literature that surgical treatment results in a better quality of life than medical therapy. ${ }^{1012}$ The newer and more objective measures of the quality of life can be used to compare groups of patients treated in different ways. Such a study might have a major impact on the attitude of practising gastroenterologists to surgical treatment for Crohn's disease.

Westminster Hospital,

B G GAZZARD

Horseferry Road,

London SW1

\section{References}

1 Truelove SC, Pena AS. Course and prognosis of Crohn's disease. Gut 1976; 17: 192-201.

2 Bergston E, Asaha H, Bergstrom J. A study of patients on chronic dialysis. Scand J Soc Med 1977; suppl II: 3-28.

3 Chambers LW, McDonald LA, Tugwell P, Buchanan WW, Kraag G. The McMaster Health Index Questionnaire as a measure of quality of life for patients with rheumatoid disease. $J$ Rheumatol 1982; 9: 780-4.

4 Kaplan RM, Atkins CJ, Timms R. Validity of a quality of well being scales as an outcome measure in chronic obstructive pulmonary disease. J Chronic Dis 1984; 37: 85-95.

5 Gazzard BG, Price HL, Libby GW, Dawson AM. The social toll of Crohn's disease. $\mathrm{Br}$ Med J 1978; ii: 1117-9.

6 Dubois R. The state of health and quality of life. Western J Med 1976; 125: 8-9.

7 Brown JS, Rowlinson ME, Hillis NC. Life satisfaction of chronic disease. Exploration of the theoretical model. Med Care 1981; 19: 1136-46.

8 Fries JF. Measuring the quality of life in relation to arthritis therapy. Postgrad Med 1983; 1: 49-56.

9 Spitzer WV, Dobson AJ, Hall J. Measuring the quality of life in cancer patients, a concise QL index for use by physicians. J Chronic Dis 1981; 34: 585-97.

10 De Dombal FT, Burton I, Goligher JC. Early and late results of surgical treatment for Crohn's disease. Br J Surg 1971; 58: 508-16.

11 Steinburg DB, Allen RN, Brooke BN, et al. Sequelae of colectomy and ileostomy. Comparison between Crohn's colitis and ulcerative colitis. Gastroenterology 1975; 68: 33-9.

12 Myers S, Walfish JS, Sachar DB, Greenstein AJ, Hill AG, Janowitz HD. Quality of life after surgery for Crohn's disease: a psychological survey. Gastroenterology 1980; 78: 1-6.

13 Crewe N. Quality of life, the ultimate goal in rehabilitation. Minnesota Med 1980; 63: 585-9.

14 Illich I. Medical nemesis: the expropriation of health. New York: Panthion Books, 1976.

15 Caputi MA. Quality of life. Model for social work practice in health care. Health and social work 1982; 7: 103-9. 